\title{
Radiative Forcing by Long-Lived Greenhouse Gases: Calculations with the AER Radiative Transfer Models
}

Michael J. Iacono, Jennifer S. Delamere, Eli J. Mlawer, Mark W. Shephard Atmospheric and Environmental Research, Inc., Lexington, Massachusetts, USA

Shepard A. Clough

Clough Associates, Lexington, Massachusetts, USA

William D. Collins

Department of Earth and Planetary Science, University of California, Berkeley, California, USA

Earth Sciences Division, Lawrence Berkeley National Laboratory, Berkeley, California, USA

Corresponding Author Address:

Michael J. lacono

Atmospheric and Environmental Research, Inc.

131 Hartwell Avenue

Lexington, MA 02421 USA

E-mail:miacono@aer.com 


\begin{abstract}
A primary component of the observed, recent climate change is the radiative forcing from increased concentrations of long-lived greenhouse gases (LLGHGs). Effective simulation of anthropogenic climate change by general circulation models (GCMs) is strongly dependent on the accurate representation of radiative processes associated with water vapor, ozone and LLGHGs. In the context of the increasing application of the Atmospheric and Environmental Research, Inc. (AER) radiation models within the GCM community, their capability to calculate longwave and shortwave radiative forcing for clear sky scenarios previously examined by the radiative transfer model intercomparison project (RTMIP) is presented. Forcing calculations with the AER line-by-line (LBL) models are very consistent with the RTMIP line-by-line results in the longwave and shortwave. The AER broadband models, in all but one case, calculate longwave forcings within a range of -0.20 to $0.23 \mathrm{~W} \mathrm{~m}^{-2}$ of LBL calculations and shortwave forcings within a range of -0.16 to $0.38 \mathrm{~W} \mathrm{~m}^{-2}$ of LBL results. These models also perform well at the surface, which RTMIP identified as a level at which GCM radiation models have particular difficulty reproducing LBL fluxes. Heating profile perturbations calculated by the broadband models generally reproduce high-resolution calculations within a few hundredths $\mathrm{K} \mathrm{d}^{-1}$ in the troposphere and within $0.15 \mathrm{~K} \mathrm{~d}^{-1}$ in the peak stratospheric heating near $1 \mathrm{hPa}$. In most cases, the AER broadband models provide radiative forcing results that are in closer agreement with highresolution calculations than the GCM radiation codes examined by RTMIP, which supports the application of the AER models to climate change research.
\end{abstract}




\section{Introduction}

A primary component of recent climate change is the radiative forcing caused by changes in concentration of the radiatively active greenhouse gases in the atmosphere. Radiative forcing is "... a measure of the influence a factor has in altering the balance of incoming and outgoing energy in the Earth-atmosphere system and is an index of the importance of the factor as a potential climate change mechanism [Solomon et al., 2007]'. Between 1750 and 2005, the radiative forcing at the top of the atmosphere due to increases in concentration of carbon dioxide, methane and nitrous oxide was $+1.66,+0.48$, and $+0.16 \mathrm{~W} \mathrm{~m}^{-2}$ respectively [Solomon et al., 2007]. Halocarbons such as $\mathrm{CCl}_{3} \mathrm{~F}$ (CFC-11) and $\mathrm{CCl}_{2} \mathrm{~F}_{2}$ ( $\left.\mathrm{CFC}-12\right)$ have contributed an additional forcing of $+0.34 \mathrm{~W} \mathrm{~m}^{-2}$ since the mid $-20^{\text {th }}$ Century resulting in a total forcing due to long-lived greenhouse gases (LLGHG) of $+2.64 \mathrm{~W} \mathrm{~m}^{-2}$ with a margin of uncertainty of ten percent. This forcing represents roughly one percent of the shortwave energy absorbed by the climate system and the longwave energy emitted by the Earth at the top of the atmosphere in a typical year, and the sign of the forcing indicates that the climate system is presently absorbing more energy than it releases. Accurate representation of these radiative processes in climate models is clearly essential to enhancing our ability to understand and to predict global climate change.

Recent research has examined the radiative forcing calculated by several coupled atmosphere-ocean general circulation models (AOGCMs) that contributed to the Intergovernmental Panel on Climate Change (IPCC) Fourth Assessment Report (AR4) and by several reference line-by-line (LBL) radiative transfer models [Collins et al., 2006, hereinafter C06]. The Radiative Transfer Model Intercomparison Project (RTMIP) conducted by C06 defined eight clear sky calculations in which the LLGHGs were specified according to various forcing scenarios that were performed by the AOGCMs for the AR4. This intercomparison concluded that while there is excellent agreement among the LBL models, there are substantial differences in forcing among the AOGCMs and between the AOGCMs and LBL models of order $0.5 \mathrm{~W} \mathrm{~m}^{-2}$ or greater [Collins et al., 2006]. The largest AOGCM forcing discrepancies were seen at the Earth's surface. Neglect of individual molecular absorbers (such as methane in the shortwave) in the AOGCMs and the radiative transfer methods utilized were both cited as reasons for the differences from the LBL codes. 
The RTMIP forcing results reported by C06 for the IPCC climate models do not include calculations with the radiation models [Clough et al., 2005] that have been developed at Atmospheric and Environmental Research, Inc. (AER) with support from the Department of Energy (DOE) Atmospheric Radiation Measurement (ARM) Program. Radiance closure studies are a critical feature of these models that enhances their wider use in climate applications. These studies provide a continual evaluation of the models with surface, aircraft and satellite measurements to quantify and to improve their accuracy [e.g. Turner et al., 2004]. This addresses the essential need to establish the accuracy of GCM radiation models through careful evaluation with measurements. This summary of radiative forcing results for the AER models following the RTMIP calculations is motivated by the wide use of the AER line-by-line model within the community and in particular by the increasing application of the AER correlated kdistribution broadband models within the GCM community. This includes the operational use of RRTMG_LW or SW in the ECMWF weather forecast system [Morcrette et al., 2008], the NCEP global forecast system (GFS) model, the Weather Research and Forecasting (WRF) model, and the ECHAM5 climate model [Wild and Roeckner, 2006] among other applications. RRTMG is also being evaluated for use in the GFDL and NCAR climate models. Details of the AER radiation models and the source code are available at the AER radiative transfer web site (www.rtweb.aer.com).

\section{Radiation Models}

LBLRTM is an accurate, efficient and highly flexible line-by-line radiative transfer model that continues to be extensively validated with measured atmospheric radiance spectra from the sub-millimeter to the ultraviolet [Clough et al., 2005; Turner et al., 2004]. LBLRTM includes all significant molecular absorbers and represents the effects of self-broadening and foreign-broadening from water vapor with the MT_CKD_v1.4 continuum model. It uses all parameters on the HITRAN 2004 database, and it includes the continua of carbon dioxide, oxygen, nitrogen, ozone as well as Rayleigh scattering extinction. The algorithmic accuracy of LBLRTM is 0.5 percent, and the limiting errors are generally attributable to the input line parameters and line shape. Integrated fluxes and heating rates are derived from LBLRTM radiance spectra with an independent program (RADSUM), which is also available at the AER 
radiative transfer web site. For the RTMIP calculations presented, LBLRTM/RADSUM utilizes three angles (six streams) for flux integration.

CHARTS (code for high-resolution accelerated radiative transfer with scattering) is a monochromatic plane-parallel radiative transfer model for the line-by-line calculation of radiances and fluxes at a single level for thermal and solar regimes in general scattering atmospheres [Moncet and Clough, 1997]. The atmosphere is treated as a vertically stratified medium in CHARTS, and individual layers are considered homogeneous in gaseous optical depth and in the cloud and aerosol optical properties. Molecular optical depths for the layers are provided by LBLRTM. Using the adding-doubling method, CHARTS efficiently treats multiple scattering for reference calculations of spectral radiances at single levels. Calculations with this model have been validated against high-resolution spectral radiance measurements [Mlawer et al., 2000]. The CHARTS algorithm is applied here to the shortwave net flux forcing calculations at the three pressure levels considered by the RTMIP intercomparison.

RRTM has been developed for both the longwave (LW) and shortwave (SW) regions as reference broadband radiative transfer models that closely reproduce line-by-line results [Mlawer et al., 1997]. Absorption coefficients for the primary and minor molecular species required for the correlated k-distribution method used by RRTM have been obtained from LBLRTM. Molecular absorbers included in RRTM are water vapor, carbon dioxide, ozone, methane, nitrous oxide, oxygen, nitrogen and the halocarbons in the longwave and water vapor, carbon dioxide, ozone, methane and oxygen in the shortwave. The water vapor continuum is based on CKD_v2.4 in the versions of RRTM applied to this work, and molecular line parameters are based on HITRAN 2000 for water vapor and HITRAN 1996 for all other molecules. Extinction from aerosols, clouds and Rayleigh scattering are also included, and the discrete-ordinates algorithm DISORT [Stamnes et al., 1988] is used for multiple scattering calculations. Several optional cloud liquid and ice parameterizations are available that allow the specification of cloud fraction and cloud physical or optical properties, though the shortwave is limited to fully clear or overcast calculations. RRTM_LW accuracy in clear sky relative to LBLRTM for flux is $1.0 \mathrm{~W} \mathrm{~m}^{-2}$ at all levels, and heating rates agree to within $0.1 \mathrm{~K} \mathrm{~d}^{-1}$ in the troposphere and $0.3 \mathrm{~K} \mathrm{~d}^{-1}$ in the stratosphere. RRTM_SW accuracy in clear sky is $1.0 \mathrm{~W} \mathrm{~m}^{-2}$ for direct flux and $2.0 \mathrm{~W} \mathrm{~m}^{-2}$ for 
diffuse flux relative to line-by-line calculations. For the RTMIP calculations presented, RRTM_LW utilizes four angles (eight streams) and RRTM_SW/DISORT uses eight angles (16 streams) for flux integration.

With the objective of providing a radiative transfer model that can be directly applied to GCMs [Iacono et al., 2003; Iacono et al., 2000] with an accuracy that is traceable to ARM and other measurements, RRTM has been modified to produce RRTMG. The former model retains the highest accuracy relative to line-by-line results for single-column calculations, and the latter provides better efficiency with minimal loss of accuracy for GCM applications. While RRTMG shares the same basic physics and absorption coefficients as RRTM, it incorporates several modifications to improve computational efficiency, to update the code formatting for easier application to GCMs, and to represent sub-grid scale cloud variability. In particular, the total number of quadrature points (g-points) used to calculate radiances in the longwave has been reduced from the standard 256 in RRTM_LW (with 16 g-points in each of the 16 spectral bands) to 140 in RRTMG_LW (with the number of g-points in each spectral band varying from 2 to 16 depending on the absorption in each band). In the shortwave, the number of g-points has been reduced from the standard 224 in RRTM_SW (with 16 in each of the 14 spectral bands) to a total of 112 in RRTMG_SW. In addition, DISORT has been replaced with a two-stream radiative transfer solver [Oreopoulos and Barker, 1999] in RRTMG_SW. Also, RRTMG has been fully reformatted for consistency between the longwave and shortwave and to incorporate modern FORTRAN90 functionality. Clear sky RRTMG_LW accuracy relative to LBLRTM for flux is $1.5 \mathrm{~W} \mathrm{~m}^{-2}$ at all levels, and heating rates agree to within $0.2 \mathrm{~K} \mathrm{~d}^{-1}$ in the troposphere and generally $0.4 \mathrm{~K} \mathrm{~d}^{-1}$ in the stratosphere. RRTMG_SW accuracy in clear sky relative to RRTM_SW is within $3 \mathrm{~W} \mathrm{~m}^{-2}$ (about 0.3 percent) for flux at all levels, and heating rates agree to within $0.1 \mathrm{~K} \mathrm{~d}^{-1}$ in the troposphere and $0.35 \mathrm{~K} \mathrm{~d}^{-1}$ (about 1 percent) in the stratosphere. For the RTMIP calculations presented here, RRTMG_LW and RRTMG_SW utilize the single standard diffusivity angle (two streams) for flux integration, though RRTMG_LW also incorporates a small modification of the diffusivity angle in some spectral bands that varies as a function of total column water vapor to improve fluxes and heating rates in profiles with high water vapor amounts. 
Due to the complexity of representing cloud overlap in the presence of multiple scattering, RRTM_SW with DISORT is limited to calculations with clear or fully overcast conditions. This limitation has been addressed for RRTMG_LW and SW with the addition of McICA, the Monte-Carlo Independent Column Approximation [Barker et al., 2002; Pincus et al., 2003], which is a statistical technique for representing sub-grid scale cloud variability including cloud overlap. This method represents cloud fraction by replacing the scalar cloud amount with a randomly sampled binary array dimensioned on g-point. Depending on its binary cloud amount of zero or one, an individual g-point is treated as fully clear or fully cloudy, respectively. Due to the highly variable contribution of each g-point to the total absorption, this method introduces random noise to the cloudy calculation of radiance, but the result has been shown to be unbiased. This approach provides the flexibility to represent the vertical correlation of the clouds (i.e. cloud overlap) in some detail by imposing an assumed relation (such as random or maximum-random) among the binary cloud arrays across the vertical dimension. Cloud physical properties (ice and liquid water path and particle sizes) or cloud optical properties (optical depth) are also dimensioned on g-point in each layer following the arrangement of the binary cloud fraction arrays, and these arrays are used in the radiative transfer to calculate total cloudy radiance. RRTMG is especially well suited to utilize McICA due to its relatively high number of g-points. However, this feature is not applied in the clear cases examined here.

\section{Radiative Forcing}

The radiative transfer calculations performed with the AER models follow the eight cases defined by $\mathrm{C} 06$, in which only the concentrations of the long-lived greenhouse gases were varied. Temperature, water vapor and ozone were specified by the standard mid-latitude summer profile, and calculations were performed over 40 vertical layers from the surface to a height of $0.01 \mathrm{hPa}$. Neither aerosols nor clouds were considered in the RTMIP calculations reported here or by C06. Radiative forcings were calculated as net flux differences between the $\mathrm{C} 06$ cases, and Table 1 lists the specific LLGHG concentration changes for each of the seven case differences examined. For example, the result for case 2a-1a is the forcing from increasing $\mathrm{CO}_{2}$ from its value of $287 \mathrm{ppmv}$ in $1860 \mathrm{AD}$ to its value of $369 \mathrm{ppmv}$ in $2000 \mathrm{AD}$, while case $2 \mathrm{~b}$-1a provides the forcing from doubling $\mathrm{CO}_{2}$ from its 1860 value to $574 \mathrm{ppmv}$. Case 3b-3a shows the forcing from increasing $\mathrm{CO}_{2}, \mathrm{CH}_{4}$ and $\mathrm{N}_{2} \mathrm{O}$ from their values in 1860 to 2000 as well as increasing the 
CFCs from zero to their present values. Other differences for cases $3 \mathrm{a}$ through $3 \mathrm{~d}$ involve various changes in the LLGHGs. Case $4 \mathrm{a}-2 \mathrm{~b}$ includes the effect of increasing water vapor in the whole column by 20 percent in the presence of doubled $\mathrm{CO}_{2}$ as a proxy for the predicted increase in $\mathrm{H}_{2} \mathrm{O}$ in a warmer climate. The shortwave forcing calculations with the AER models depart from the C06 RTMIP specification in that the former were performed over the $820-50000 \mathrm{~cm}^{-1}(0.2$ $12.2 \mu \mathrm{m})$ spectral range with a solar constant of $1368.2 \mathrm{~W} \mathrm{~m}^{-2}$. The C06 calculations used a spectral range $0.2-5.0 \mu \mathrm{m}$ and a reduced solar constant of $1360 \mathrm{~W} \mathrm{~m}^{-2}$ to accommodate this spectral limit in the GCM radiation models studied by C06. The contribution of the 5.0-12.2 $\mu \mathrm{m}$ region to the total solar forcing for the cases examined is $0.01 \mathrm{~W} \mathrm{~m}^{-2}$ or less, except for a $0.05 \mathrm{~W}$ $\mathrm{m}^{-2}$ contribution to the total forcing in case $4 \mathrm{a}-2 \mathrm{~b}$ at the surface.

While the results for the IPCC GCMs and several LBL models were presented by C06 as inter-model averages and standard deviations, the radiative forcings for the AER codes are presented here for each model individually. The longwave radiative forcing based on net flux calculations at the top of the atmosphere, at $200 \mathrm{hPa}$, and at the surface is listed in Table 2 for LBLRTM_v11.1, RRTM_LW_v3.2 and RRTMG_LW_v4.4. These can be compared with Table 8 in C06, which summarizes the GCM and line-by-line results for the longwave models examined in that study. For each case and at each of the three vertical levels, the radiative forcing calculated by LBLRTM is within $0.06 \mathrm{~W} \mathrm{~m}^{-2}$ of the mean LBL model result of C06. In most cases, the LBLRTM forcing is slightly higher than the C06 mean LBL forcing. The exception is case 3a-1a (the forcing from increasing the $\mathrm{CH}_{4}$ and $\mathrm{N}_{2} \mathrm{O}$ concentrations from zero to their 1860 values), for which the LBLRTM result is slightly lower than the C06 mean LBL result. For all cases and at all three levels, the difference between the LBLRTM forcing and the mean C06 LBL result is generally less than the standard deviation of the C06 LBL forcing values. Radiative forcing differences at the top of the atmosphere between the AER broadband longwave models and LBLRTM range from -0.20 to $0.23 \mathrm{~W} \mathrm{~m}^{-2}$ depending on the case with the exception of case 3a-1a for which RRTM_LW and RRTMG_LW are about $0.55 \mathrm{~W} \mathrm{~m}^{-2}$ lower than the line-by-line result. The later difference results from known minor deficiencies in the methane and nitrous oxide spectroscopic treatment in the broadband models, which is being addressed for future versions of these models. Although these differences are consistent with the differences between the mean GCM and LBL results $\left(-0.35\right.$ to $\left.0.17 \mathrm{~W} \mathrm{~m}^{-2}\right)$ shown by C06, it 
should be noted that the standard deviation of radiative forcing at the top of the atmosphere for the C06 GCM models varies from 0.13 to $0.82 \mathrm{~W} \mathrm{~m}^{-2}$ among the seven forcing cases. This suggests that some of the individual GCM model differences in the C06 study are considerably larger than the mean difference. At $200 \mathrm{hPa}$, the AER broadband model differences from LBLRTM range from -0.17 to $0.22 \mathrm{~W} \mathrm{~m}^{-2}$ in all cases except for a forcing difference of $0.35 \mathrm{~W}$ $\mathrm{m}^{-2}$ for case 3a-1a. The mean C06 GCM model forcings at this level have a range of -0.42 to $0.06 \mathrm{~W} \mathrm{~m}^{-2}$ in difference from the mean C06 LBL result and a range in forcing standard deviation of 0.15 to $0.73 \mathrm{~W} \mathrm{~m}^{-2}$. At the surface, the AER broadband models perform especially well relative to LBLRTM with differences of $0.11 \mathrm{~W} \mathrm{~m}^{-2}$ or less in all cases, except for a difference of $0.37 \mathrm{~W} \mathrm{~m}^{-2}$ between RRTMG_LW and LBLRTM in case $4 \mathrm{a}-2 \mathrm{~b}$ (the forcing from increasing water by 20 percent with doubled $\mathrm{CO}_{2}$ ). By contrast, the difference in mean forcing for the GCM and LBL models examined by $\mathrm{C} 06$ varies from -0.52 to $0.67 \mathrm{~W} \mathrm{~m}^{-2}$ at the surface across the seven cases. The standard deviation of surface longwave forcing among the C06 GCM models ranges from 0.13 to $0.87 \mathrm{~W} \mathrm{~m}^{-2}$. The impact of the water vapor continuum change between LBLRTM (MT_CKD_1.4) and RRTM/RRTMG (CKD_2.4) on case $4 a-2 b$ is $0.01 \mathrm{~W} \mathrm{~m}^{-}$ 2 or less at the top of the model and at $200 \mathrm{hPa}$, and it reduces the forcing by about $0.1 \mathrm{~W} \mathrm{~m}^{-2}$ at the surface (though the impact is as large as $0.3 \mathrm{~W} \mathrm{~m}^{-2}$ in the middle troposphere). Finally, it is notable that the AER accelerated broadband model, RRTMG, performs well relative to RRTM in the longwave with differences generally less than $0.05 \mathrm{~W} \mathrm{~m}^{-2}$ except for case $4 \mathrm{a}-2 \mathrm{~b}$, where differences are $0.1 \mathrm{~W} \mathrm{~m}^{-2}$ at the tropopause and above and $0.37 \mathrm{~W} \mathrm{~m}^{-2}$ at the surface.

The shortwave radiative forcing results are summarized in Table 3 for CHARTS_v4.03, RRTM_SW_v2.7 and RRTMG_SW_v3.5. The CHARTS calculations used optical depths derived from LBLRTM_v11.1. These results can be compared with Table 9 in C06, which summarizes the GCM and line-by-line results for the shortwave models examined in that study. For each case and at each of the three vertical levels, the radiative forcing calculated by CHARTS is within $0.05 \mathrm{~W} \mathrm{~m}^{-2}$ of the mean LBL model result of C06, except for case $4 \mathrm{a}-2 \mathrm{~b}$. In the latter case, CHARTS forcings are $0.08 \mathrm{~W} \mathrm{~m}^{-2}$ lower at $200 \mathrm{hPa}$ and $0.37 \mathrm{~W} \mathrm{~m}^{-2}$ lower at the surface than the mean C06 line-by-line result. CHARTS calculations were also performed for the truncated $0.2-5 \mu \mathrm{m}$ spectral range used by the RTMIP shortwave models, and for this range CHARTS is within $0.06 \mathrm{~W} \mathrm{~m}^{-2}$ at $200 \mathrm{hPa}$ and $0.32 \mathrm{~W} \mathrm{~m}^{-2}$ at the surface of the mean C06 LBL 
result in case $4 \mathrm{a}-2 \mathrm{~b}$. At the top of the atmosphere, radiative forcing differences between the AER broadband models and CHARTS range from -0.10 to $0 \mathrm{~W} \mathrm{~m}^{-2}$ in all cases. Since RRTM_SW and RRTMG_SW include methane and nitrous oxide, which were not treated in the C06 GCM shortwave models, the former models provide an improved result in cases that included these gases. At $200 \mathrm{hPa}$, the AER broadband model forcing differences from CHARTS range from -0.16 to $0.04 \mathrm{~W} \mathrm{~m}^{-2}$ over all cases. The difference in the C06 mean GCM and mean LBL model forcings at this level range from -0.13 to $0.35 \mathrm{~W} \mathrm{~m}^{-2}$ and a forcing standard deviation range of 0.09 to $0.28 \mathrm{~W} \mathrm{~m}^{-2}$. Finally, at the surface the AER broadband model forcing differences from CHARTS range from 0.02 to $0.38 \mathrm{~W} \mathrm{~m}^{-2}$ over all cases except for a $0.59 \mathrm{~W} \mathrm{~m}^{-2}$ difference in case 3a-1a. The mean model forcing differences between the C06 GCM and LBL results at this level range from -0.50 to $0.98 \mathrm{~W} \mathrm{~m}^{-2}$, and the forcing standard deviation ranges from 0.46 to $1.40 \mathrm{~W} \mathrm{~m}^{-2}$. This illustrates the significant improvement in shortwave forcing provided by the AER broadband models for the C06 RTMIP cases, especially at the surface, though further improvements are being investigated.

\section{Heating Rates}

Heating rate profiles are also affected by changes in LLGHGs through the impact on the net flux divergence. For example, doubling the concentration of carbon dioxide increases absorption of upwelling longwave radiation and reduces the upward longwave flux at the tropopause by about $4 \mathrm{~W} \mathrm{~m}^{-2}$. Emission of downward longwave radiation increases by as much as $4 \mathrm{~W} \mathrm{~m}^{-2}$ in the middle troposphere and by about $2 \mathrm{~W} \mathrm{~m}^{-2}$ at the tropopause and surface. This results in a decrease in net flux divergence in the lower troposphere and an increase in longwave radiative heating of up to $0.1 \mathrm{~K} \mathrm{~d}^{-1}$ at these levels. The change in the longwave heating rate profile from doubling the $\mathrm{CO}_{2}$ concentration from its 1860 amount is shown in the left panels of Figure 1 for the AER line-by-line and broadband radiation models. In this and subsequent figures, results are shown from the surface to $0.1 \mathrm{hPa}$ in the upper panels and from the troposphere up to $100 \mathrm{hPa}$ in the lower panels. In the stratosphere, the net flux divergence is increased, which results in a substantial reduction in longwave heating (enhancement in longwave cooling) at the $1 \mathrm{hPa}$ level. In general, the AER broadband models very closely reproduce the changes in heating rate calculated by LBLRTM throughout the column. The largest departures of about 10 percent occur at and just below the stratospheric peak in longwave 
cooling. Changes in the shortwave heating profile for the doubled $\mathrm{CO}_{2}$ forcing case are shown in the right panels of Figure 1 for the two AER broadband models only. Shortwave heating rate calculations with CHARTS for the full profile were not performed due to the excessive computational effort required. RRTM and RRTMG generate very similar results with the exception of differences of a few hundredths $\mathrm{K} \mathrm{d}^{-1}$ just below the tropopause and near the $1 \mathrm{hPa}$ peak in stratospheric heating. The ability of the AER broadband models to reproduce the line-byline forcing in radiative heating throughout most of the column is noticeably better than the C06 GCM radiation models. As shown in Figure 10 of C06, the GCM models studied in RTMIP generate results that vary considerably with some closely reproducing the line-by-line profile of heating rate perturbations while others oscillate around it by as much as $0.1 \mathrm{~K} \mathrm{~d}^{-1}$. Similar conclusions can be drawn from the other RTMIP cases.

Perturbations in the heating rate profiles from increasing the LLGHG concentrations from their 1860 to 2000 values (case 3b-3a) as calculated by the AER models are shown in Figure 2. Once again, the broadband models closely reproduce the change in heating calculated by LBLRTM in the longwave (left panels) through most of the vertical regime. Notable deviations include a roughly 10 percent overestimate of the increase in longwave cooling at the 1 $\mathrm{hPa}$ level by the broadband models and small differences of $0.01 \mathrm{~K} \mathrm{~d}^{-1}$ or less in the troposphere. In the shortwave (right panels of Figure 2), the broadband models produce nearly identical changes in heating throughout the profile with the largest difference of $0.01 \mathrm{~K} \mathrm{~d}^{-1}$ occurring just below the tropopause.

Heating rate profile changes that result from increasing water vapor by 20 percent in the presence of doubled carbon dioxide are shown for the AER models in Figure 3. In the longwave (left panels), RRTM very closely reproduces the LBLRTM result in the lower troposphere, with RRTMG differing from the line-by-line calculation by no more than $0.05 \mathrm{~K} \mathrm{~d}^{-1}$ in the layers near surface. Above the middle troposphere, the two broadband models are nearly identical with differences from LBLRTM of a few hundredths $\mathrm{K} \mathrm{d}^{-1}$ or less. The increase in water vapor enhances longwave cooling at all levels. In the shortwave, the two broadband models produce essentially identical results and increase shortwave heating in the troposphere by just under $0.1 \mathrm{~K}$ $\mathrm{d}^{-1}$ with generally smaller heating increases in the stratosphere. By contrast, Figure 13 in C06 
shows that the heating perturbations for this case among the RTMIP GCM models differ by up to $0.1 \mathrm{~K} \mathrm{~d}^{-1}$ at various levels in the troposphere in the longwave and shortwave. Slight differences of a few hundredths $\mathrm{K} \mathrm{d}^{-1}$ in heating rate are also apparent among the $\mathrm{C} 06$ line-by-line models. In the shortwave, the AER broadband heating rate calculations in Figure 3 are in excellent agreement with the $\mathrm{C} 06$ solar line-by-line model results.

\section{Conclusions}

This paper summarizes the result of producing the clear sky radiative forcing calculations of the Radiative Transfer Model Intercomparison Project (RTMIP) of Collins et al. [2006] with the AER radiation models. The wide use by the community of the line-by-line model, LBLRTM, and the increasing use of the broadband correlated k-distribution models RRTM and RRTMG for single-column and GCM applications, respectively, has motivated this comparison of the AER models to the line-by-line and IPCC AR4 models examined in the RTMIP experiment. Radiative forcing by individual long-lived greenhouse gases since the mid- $18^{\text {th }}$ Century is on the order of 1 $\mathrm{W} \mathrm{m}^{-2}$ or less. Therefore, highly accurate radiative transfer in GCMs is essential to model effectively the radiative contribution of LLGHGs to global climate change.

In general, LBLRTM and CHARTS calculate radiative forcings that are in close agreement with the line-by-line models studied by $\mathrm{C} 06$, and in most cases the AER broadband models calculate forcings that are in better agreement with the line-by-line results than the mean of the C06 GCM radiation models. Among the seven cases and three levels studied (top of the atmosphere, $200 \mathrm{hPa}$, and surface), LBLRTM longwave forcings differ by $0.06 \mathrm{~W} \mathrm{~m}^{-2}$ or less from the mean C06 line-by-line model result, and the differences are generally less than the standard deviation of the latter models within each case. In all but one case, the LBLRTM forcing is slightly higher than the C06 mean line-by-line model forcing. In the shortwave, CHARTS forcings are within $0.05 \mathrm{~W} \mathrm{~m}^{-2}$ of the mean C06 line-by-line result, except for slightly larger differences in the case with increased water vapor.

In all cases except one, the AER broadband models calculate longwave forcings that are within a range of -0.20 to $0.23 \mathrm{~W} \mathrm{~m}^{-2}$ of LBLRTM, and more than half of the results are within $0.10 \mathrm{~W} \mathrm{~m}^{-2}$. The primary exception is the case in which the concentrations of methane and 
nitrous oxide were increased from zero to their $19^{\text {th }}$ century values, in which RRTM and RRTMG produce $0.55 \mathrm{~W} \mathrm{~m}^{-2}$ less forcing than the line-by-line result at the top of the atmosphere and $0.35 \mathrm{~W} \mathrm{~m}^{-2}$ less forcing at the tropopause. Although the cause of this discrepancy in RRTM and RRTMG is being investigated and corrected, it should be noted that this case among those considered by RTMIP is the scenario that is least relevant to analyses of recent climate change. By contrast, the mean longwave forcing calculated by the C06 GCM models differs from the line-by-line calculations over a range from -0.52 to $0.67 \mathrm{~W} \mathrm{~m}^{-2}$, with the largest discrepancies at the surface, and about one-third of the mean results are within than $0.10 \mathrm{~W} \mathrm{~m}^{-2}$. In the shortwave, since the RTMIP GCM shortwave models did not include methane and nitrous oxide as noted by $\mathrm{C} 06$, the AER broadband models, which do include these gases, provide forcing calculations that are more comparable to the higher resolution models in most cases. In all cases except one, the AER broadband models calculate shortwave forcings within a range of -0.16 to $0.38 \mathrm{~W} \mathrm{~m}^{-2}$ of CHARTS. As in the longwave, the exception occurs for the case in which methane and nitrous oxide are increased from zero to $19^{\text {th }}$ century values where the broadband model forcings are $0.59 \mathrm{~W} \mathrm{~m}^{-2}$ lower than the line-by-line result. By contrast, the mean shortwave forcing calculated by the $\mathrm{C} 06 \mathrm{GCM}$ models differs from the line-by-line calculations over a range from -0.50 to $0.98 \mathrm{~W} \mathrm{~m}^{-2}$. Finally, the surface was identified by $\mathrm{C} 06$ as the level at which the largest discrepancies occur between the RTMIP AOGCMs and LBL models, and that study noted that particular attention should be given to model evaluation at this level. This analysis shows that the AER broadband models perform especially well at the surface relative to line-by-line calculations in the longwave. Although some discrepancies remain in the shortwave that are being investigated, significant improvement is noted relative to the C06 GCM shortwave models.

Changes in LLGHGs impact radiative heating profiles as well as fluxes, and the AER broadband models calculate heating perturbations for the RTMIP cases that are generally very consistent with LBL model calculations. In most cases in the longwave, differences between the broadband and line-by-line model heating rates are within a few hundredths $\mathrm{K} \mathrm{d}^{-1}$ in the troposphere and $0.15 \mathrm{~K} \mathrm{~d}^{-1}$ in the stratospheric peak. Shortwave heating profiles were not calculated with the AER LBL model for this study, but the AER broadband heating rate perturbations are in excellent agreement with the C06 solar LBL model calculations. The AER radiation models undergo continual validation with measurements or evaluation against higher 
resolution models, and this intercomparison of radiative forcing calculations demonstrates their consistency, their accuracy relative to other widely used models, and their suitability for an extensive range of research and climate change applications.

\section{Acknowledgments}

The authors would like to thank Andrew Conley (NCAR) for providing the atmospheric profiles and information necessary to reproduce the RTMIP forcing experiments with the AER models. We also acknowledge the helpful comments of two anonymous reviewers. This research was supported by the Office of Biological and Environmental Research of the U.S. Department of Energy under Grant No. DE-FG02-92ER61549 as part of the Atmospheric Radiation Measurement Program. This work was also supported by the Director, Office of Science, of the U.S. Department of Energy under Contract No. DE-AC02-05CH11231 and by the National Science Foundation Center for Multiscale Modeling of Atmospheric Processes. 


\section{References}

Barker, H. W., R. Pincus, and J.-J. Morcrette (2002), The Monte Carlo Independent Column Approximation: Application within large-scale models, paper presented at the GCSS-ARM Workshop on the Representation of Cloud Systems in Large-Scale Models, Kananaskis, Alberta, Canada, 20-24 May.

Clough, S. A., M. W. Shephard, E. J. Mlawer, J. S. Delamere, M. J. Iacono, K. Cady-Pereira, S. Boukabara, P. D. Brown (2005), Atmospheric radiative transfer modeling: A summary of the AER codes, J. Quant. Spectrosc. Radiat. Transfer, 91, 233-244.

Collins, W. D., et al. (2006), Radiative forcing by well-mixed greenhouse gases: Estimates from climate models in the Intergovernmental Panel on Climate Change (IPCC) Fourth Assessment Report (AR4), J. Geophys. Res., 111, D14317, doi:10.1029/2005JD006713.

Iacono, M. J., J. S. Delamere, E. J. Mlawer, and S. A. Clough (2003), Evaluation of upper tropospheric water vapor in the NCAR community climate model (CCM3) using modeled and observed HIRS radiances, J. Geophys. Res., 108(D2), 4037, doi:10.1029/2002JD002539.

Iacono, M. J., E. J. Mlawer, S. A. Clough, and J.-J. Morcrette (2000), Impact of an improved longwave radiation model, RRTM, on the energy budget and thermodynamic properties of the NCAR community climate model, CCM3, J. Geophys. Res., 105, 14,873-14,890.

Mlawer, E. J., P. D. Brown, S. A. Clough, L. C. Harrison, J. J. Michalsky, P. W. Kiedron, and T. Shippert (2000), Comparison of spectral direct and diffuse solar irradiance measurements and calculations for cloud-free conditions, Geophys. Res. Lett., 27, 2653-2656.

Mlawer, E. J., S. J. Taubman, P. D. Brown, M. J. Iacono, and S. A. Clough (1997), Radiative transfer for inhomogeneous atmospheres: RRTM, a validated correlated-k model for the longwave, J. Geophys. Res., 102, 16,663-16,682.

Moncet, J.-L., and S. A. Clough (1997), Accelerated monochromatic radiative transfer for scattering atmospheres: Application of a new model to spectral radiance observations, $J$. Geophys. Res., 102, 21,853-21,866.

Morcrette, J.-J., H. W. Barker, J. N. S. Cole, M. J. Iacono, and R. Pincus (2008), Impact of a new radiation package, McRad, in the ECMWF Integrated Forecasting System, Mon. Weather Rev., in press.

Oreopoulos, L., and H. W. Barker (1999), Accounting for subgrid-scale cloud variability in a multi-layer 1-D solar radiative transfer algorithm, Q. J. R. Meteorol. Soc., 125, 301-330.

Pincus, R., H. W. Barker, and J.-J. Morcrette (2003), A fast, flexible, approximate technique for computing radiative transfer in inhomogeneous cloud fields, J. Geophys. Res., 108(D13), 4376, doi:10.1029/2002JD003322. 
Solomon, S., et al. (2007), Technical Summary, In: Climate Change 2007: The Physical Science Basis. Contribution of Working Group I to the Fourth Assessment Report of the Intergovernmental Panel on Climate Change, edited by S. Solomon, D. Qin, M. Manning, Z. Chen, M. Marquis, K. B. Averyt, M. Tignor and H. L. Miller, Cambridge Univ. Press, Cambridge, United Kingdom and New York.

Stamnes, K., S. C. Tsay, W. Wiscombe, and K. Jayaweera (1988), A numerically stable algorithm for discrete-ordinate-method radiative transfer in scattering and emitting layered media, Appl. Opt., 27, 2502-2509.

Turner, D. D., et al. (2004): The QME AERI LBLRTM: A closure experiment for downwelling high spectral resolution infrared radiance, J. Atmos. Sci., 61, 2657-2675.

Wild, M., and E. Roeckner (2006), Radiative fluxes in the ECHAM5 general circulation model, J. Climate, 19, 3792-3809. 
Figure captions

Figure 1. Heating rate profile changes from doubling the $\mathrm{CO}_{2}$ concentration from 287 to 574 ppmv using the standard mid-latitude summer profile for the longwave (left) and shortwave (right) from the surface to $0.1 \mathrm{hPa}$ (top) and the troposphere (bottom) as calculated by the AER radiation models.

Figure 2. Heating rate profile changes from increasing the concentrations of $\mathrm{CO}_{2}, \mathrm{CH}_{4}, \mathrm{~N}_{2} \mathrm{O}$, CFC-11 and CFC-12 from 1860 to 2000 values using the standard mid-latitude summer profile for the longwave (left) and shortwave (right) from the surface to $0.1 \mathrm{hPa}$ (top) and the troposphere (bottom) as calculated by the AER radiation models.

Figure 3. Heating rate profile changes from increasing the water vapor concentration in the standard mid-latitude summer profile in all layers by 20 percent with doubled $\mathrm{CO}_{2}(574 \mathrm{ppmv})$ in all calculations for the longwave (left) and shortwave (right) from the surface to $0.1 \mathrm{hPa}$ (top) and the troposphere (bottom) as calculated by the AER radiation models. 
Table 1. Changes in Atmospheric Constituents for the Radiative Forcing Calculations [from Collins et al., 2006]

\begin{tabular}{|c|c|c|c|c|c|c|}
\hline Case & $\mathrm{CO}_{2}(\mathrm{ppmv})$ & $\mathrm{CH}_{4}(\mathrm{ppbv})$ & $\mathrm{N}_{2} \mathrm{O}(\mathrm{ppbv})$ & $\mathrm{CFC}-11(\mathrm{pptv})$ & $\mathrm{CFC}-12(\mathrm{pptv})$ & $\mathrm{H}_{2} \mathrm{O}^{\mathrm{a}}$ \\
\hline $2 \mathrm{a}-1 \mathrm{a}$ & $287 \rightarrow 369$ & --- & --- & --- & --- & --- \\
\hline $2 \mathrm{~b}-1 \mathrm{a}$ & $287 \rightarrow 574$ & --- & --- & --- & --- & --- \\
\hline $3 \mathrm{~b}-3 \mathrm{a}$ & $287 \rightarrow 369$ & $806 \rightarrow 1760$ & $275 \rightarrow 316$ & $0 \rightarrow 267$ & $0 \rightarrow 535$ & --- \\
\hline $3 \mathrm{a}-1 \mathrm{a}$ & --- & $0 \rightarrow 806$ & $0 \rightarrow 275$ & --- & --- & --- \\
\hline $3 \mathrm{~b}-3 \mathrm{c}$ & --- & --- & $275 \rightarrow 316$ & $0 \rightarrow 267$ & $0 \rightarrow 535$ & --- \\
\hline $3 \mathrm{~b}-3 \mathrm{~d}$ & --- & $806 \rightarrow 1760$ & --- & $0 \rightarrow 267$ & $0 \rightarrow 535$ & --- \\
\hline $4 \mathrm{a}-2 \mathrm{~b}$ & --- & --- & --- & --- & -- & $1.0 \rightarrow 1.2$ \\
\hline
\end{tabular}

${ }^{a}$ Value listed for $\mathrm{H}_{2} \mathrm{O}$ is the change in the multiplier applied to the water vapor mixing ratio in the reference MLS profile. 
Table 2. Longwave Radiative Forcing ${ }^{a}$

\begin{tabular}{|c|c|c|c|c|c|c|c|c|}
\hline & & \multicolumn{7}{|c|}{ Forcing Cases } \\
\hline Level & Field & $2 a-1 a$ & $2 \mathrm{~b}-1 \mathrm{a}$ & $3 b-3 a$ & $3 a-1 a$ & $3 b-3 c$ & $3 b-3 d$ & $4 a-2 b$ \\
\hline TOM & $\mathrm{F}_{\text {RRTMG_LW }}$ & 1.10 & 3.07 & 2.07 & 3.07 & 0.56 & 0.78 & 3.77 \\
\hline TOM & $\mathrm{F}_{\text {RRTM_LW }}$ & 1.10 & 3.05 & 2.09 & 3.04 & 0.58 & 0.80 & 3.87 \\
\hline TOM & $\mathrm{F}_{\text {LBLRTM }}$ & 1.03 & 2.84 & 2.15 & 3.60 & 0.54 & 0.98 & 3.79 \\
\hline $200 \mathrm{hPa}$ & $\mathrm{F}_{\text {RRTMG_LW }}$ & 2.04 & 5.74 & 2.98 & 3.10 & 0.47 & 0.76 & 4.63 \\
\hline $200 \mathrm{hPa}$ & $\mathrm{F}_{\text {RRTM_LW }}$ & 2.05 & 5.76 & 3.01 & 3.10 & 0.49 & 0.78 & 4.72 \\
\hline $200 \mathrm{hPa}$ & $\mathrm{F}_{\text {LBLRTM }}$ & 1.98 & 5.54 & 3.06 & 3.45 & 0.46 & 0.93 & 4.52 \\
\hline Surface & $\mathrm{F}_{\text {RRTMG_LW }}$ & 0.57 & 1.79 & 1.05 & 1.15 & 0.35 & 0.42 & 11.92 \\
\hline Surface & $\mathrm{F}_{\text {RRTM_LW }}$ & 0.56 & 1.73 & 1.00 & 1.12 & 0.33 & 0.39 & 11.55 \\
\hline Surface & $\mathrm{F}_{\text {LBLRTM }}$ & 0.57 & 1.68 & 1.10 & 1.08 & 0.31 & 0.48 & 11.55 \\
\hline
\end{tabular}

${ }^{\mathrm{a}}$ Units are in $\mathrm{W} \mathrm{m} \mathrm{m}^{-2}$. 
Table 3. Shortwave Radiative Forcing ${ }^{\mathrm{a}}$

\begin{tabular}{|c|l|c|c|c|c|c|c|c|}
\hline \multicolumn{2}{|c|}{} & \multicolumn{7}{|c|}{ Forcing Cases } \\
\hline Level & Field & 2a-1a & $2 \mathrm{~b}-1 \mathrm{a}$ & $3 \mathrm{~b}-3 \mathrm{a}$ & $3 \mathrm{a}-1 \mathrm{a}$ & $3 \mathrm{~b}-3 \mathrm{c}$ & $3 \mathrm{~b}-3 \mathrm{~d}$ & $4 \mathrm{a}-2 \mathrm{~b}$ \\
\hline TOM & $\mathrm{F}_{\text {RRTMG_Sw }}$ & 0.02 & 0.06 & 0.07 & 0.05 & 0.00 & 0.05 & 0.75 \\
\hline $\mathrm{TOM}$ & $\mathrm{F}_{\text {RRTM_Sw }}$ & 0.02 & 0.07 & 0.07 & 0.04 & 0.00 & 0.05 & 0.75 \\
\hline $\mathrm{TOM}$ & $\mathrm{F}_{\text {CHARTS }}$ & 0.04 & 0.12 & 0.13 & 0.14 & 0.00 & 0.08 & 0.77 \\
\hline $200 \mathrm{hPa}$ & $\mathrm{F}_{\text {RRTMG_Sw }}$ & -0.31 & -0.92 & -0.52 & -0.29 & 0.00 & -0.21 & 0.47 \\
\hline $200 \mathrm{hPa}$ & $\mathrm{F}_{\text {RRTM_Sw }}$ & -0.26 & -0.77 & -0.42 & -0.24 & 0.00 & -0.16 & 0.47 \\
\hline $200 \mathrm{hPa}$ & $\mathrm{F}_{\text {} \text { CHARTS }}$ & -0.26 & -0.76 & -0.44 & -0.40 & -0.02 & -0.16 & 0.43 \\
\hline Surface & $\mathrm{F}_{\text {RRTMG_SW }}$ & -0.21 & -0.57 & -0.53 & -0.31 & 0.00 & -0.32 & -6.14 \\
\hline Surface & $\mathrm{F}_{\text {RRTM_Sw }}$ & -0.21 & -0.59 & -0.54 & -0.31 & 0.00 & -0.33 & -6.19 \\
\hline Surface & $\mathrm{F}_{\text {CHARTS }}$ & -0.31 & -0.95 & -0.87 & -0.90 & -0.02 & -0.54 & -6.24 \\
\hline
\end{tabular}

${ }^{\mathrm{a}}$ Units are in $\mathrm{W} \mathrm{m}^{-2}$. 

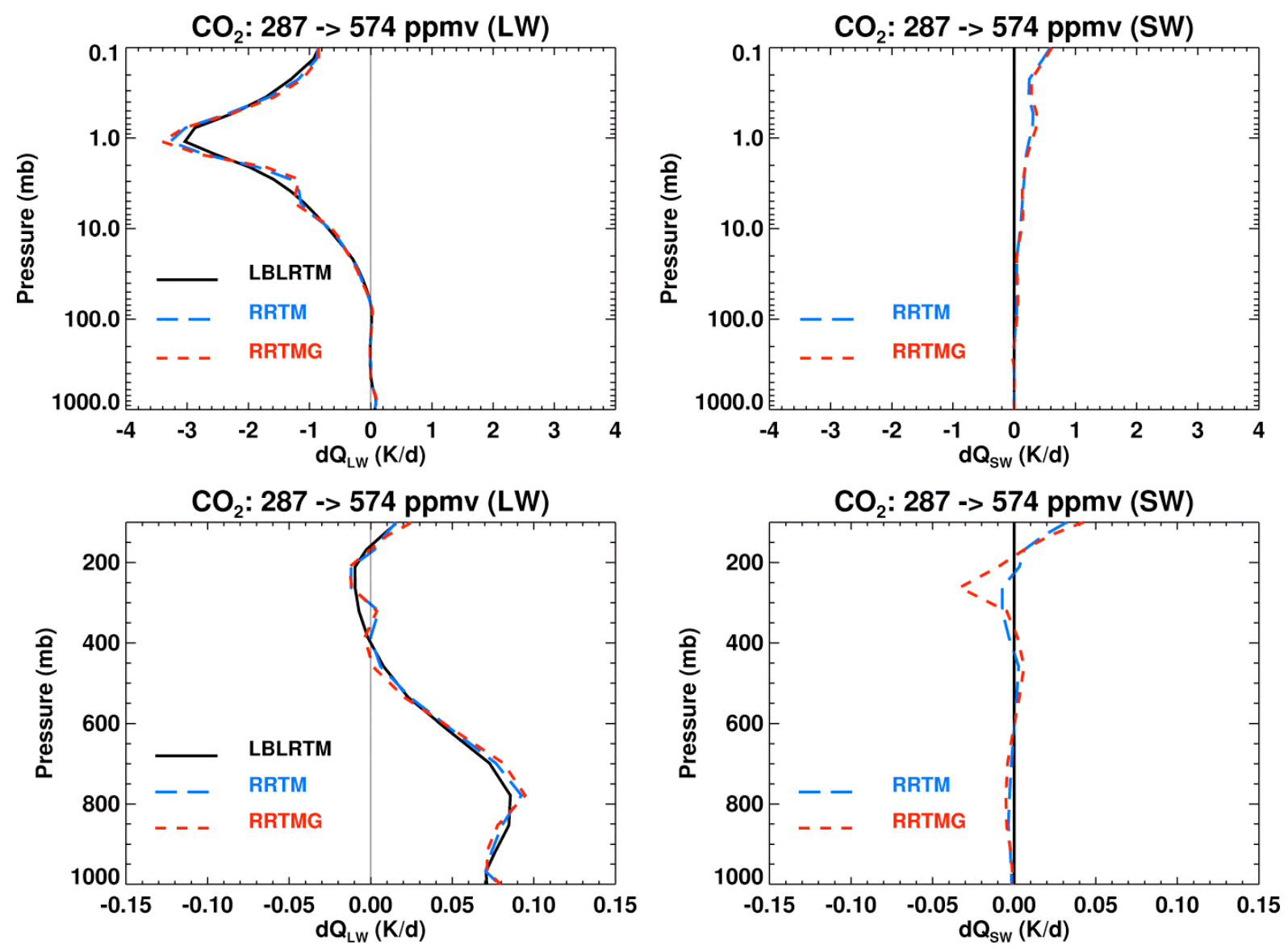

Figure 1. Heating rate profile differences from doubling the $\mathrm{CO}_{2}$ concentration from 287 to 574 ppmv using the standard mid-latitude summer profile for the longwave (left) and shortwave (right) as calculated by the AER radiation models. 

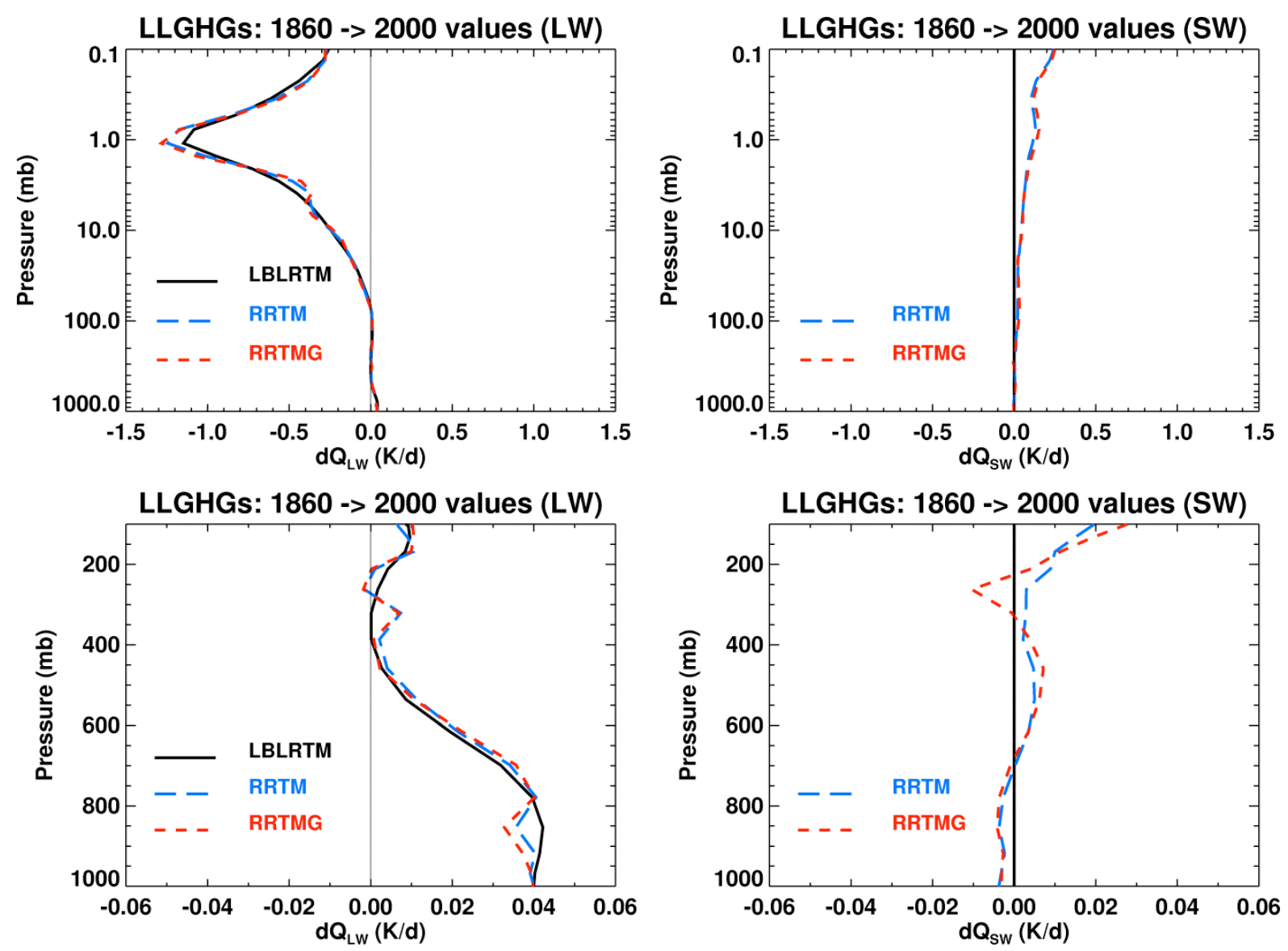

Figure 2. Heating rate profile differences from increasing the concentrations of $\mathrm{CO}_{2}, \mathrm{CH}_{4}, \mathrm{~N}_{2} \mathrm{O}, \mathrm{CFC}-11$ and CFC12 from 1860 to 2000 values using the standard mid-latitude summer profile for the longwave (left) and shortwave (right) as calculated by the AER radiation models. 

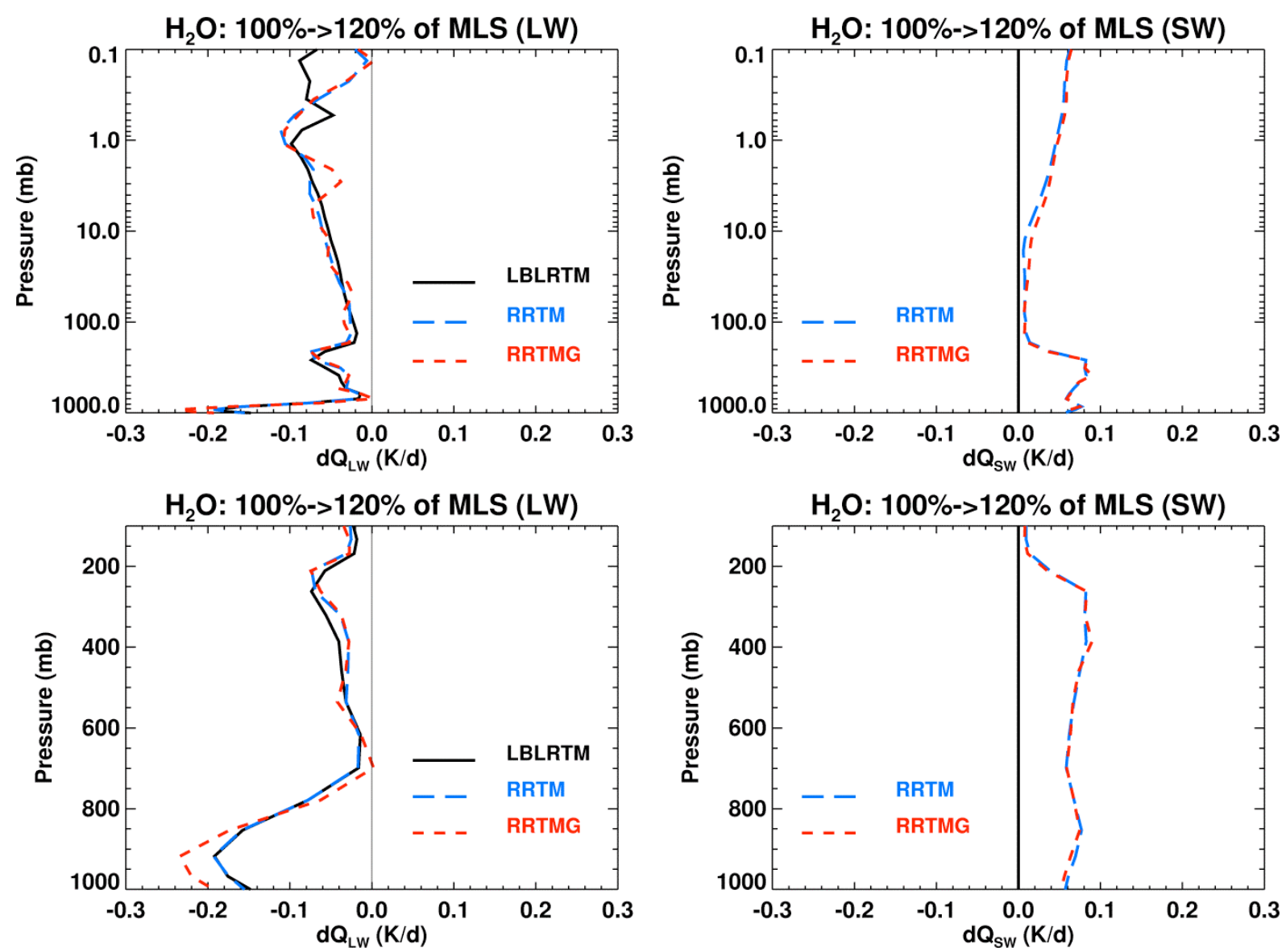

Figure 3. Heating rate profile differences from increasing the water vapor concentration in the standard mid-latitude summer profile in all layers by 20 percent with doubled $\mathrm{CO}_{2}(574 \mathrm{ppmv})$ in all calculations for the longwave (left) and shortwave (right) as calculated by the AER radiation models. 